\title{
Lexical Temporal Indicators: How do they Affect Beginning Learners' Comprehension and Processing a Morphosyntactic Feature?
}

\author{
AfsAr Rouhi \\ Payame Noor University, Ardabil, IRAN \\ Mina Alawizadeh \\ Islamic Azad University (Ardabil Branch), Ardabil, IRAN
}

Received: 11 May 2010 / Accepted: 10 August 2010

ISSN: 1697-7467

\begin{abstract}
This study explores the competitive relationship between form and meaning in getting attention based on the primacy of meaning principle and the lexical preference principle (VanPatten, 2004a). With this end in view 161 participants were assigned to four experimental conditions: Silent reading with $(+)$ and without $(-)$ LTIs and thinkaloud with $(+)$ and without $(-)$ LTIs. +LTIs groups read a passage with a title referring to the past, 14 target forms -ed and 12 LTIs. «LTIs groups read a version of the passage with 14 target forms, with no title and LTIs associated with the temporal morphology. To identify the degree of text comprehension resulting from different conditions, all groups took a comprehension test while the degree of form processing was examined through a form-recognition test, a cloze-passage production test, and a translation test. A two-way ANOVA run on the data obtained from the comprehension test showed statistically main effect for +LTIs. Two-way ANOVAs run on the data obtained from the three tests examining the effects of "LTIs on participants' engagement with L2 form processing showed some benefits. The results obtained for text interaction formats measured by comprehension test showed no benefit. Input processing made benefit from think-aloud protocol measured by cloze-passage and translation tests and not from form-recognition test. The interaction of $\pm \mathrm{LT}$ Is and text interaction formats did not influence comprehension; however, input processing was influenced by the interaction of \pm LTIs and text interaction formats.
\end{abstract}

Keywords: Input processing, Comprehension, Lexical temporal indicators

Los indicadores léxico-temporales: ¿cómo afectan a la comprensión y al procesamiento morfosintáctico de los alumnos principiantes?

RESUMEN: Este estudio explora, según el principio de la primacía del significado y el principio de la preferencia léxica postulados por VanPatten (2004a), los límites de la capacidad de atención cuando los estudiantes de una segunda lengua requieren procesar el significado y la forma. Para tal efecto, 161 participantes fueron asignados a una de las cuatro condiciones experimentales siguientes: Lectura en silencio con $(+)$ y $\sin$ $(-)$ ILT, indicadores léxico-temporales, y pensamiento en voz alta con $(+)$ y $\sin (-)$ ILTs. Los grupos en la condición +ILT leyeron un texto con un título que hacia referencia al pasado, 14 verbos con la terminación del pasado regular del inglés (-ed) y 12 ILTs. 
Los grupos bajo la condición -ILT leyeron el texto con los 14 verbos en pasado, pero sin título y sin ILTs asociados a la morfología temporal. Para identificar la capacidad de comprensión del significado del texto en las cuatro condiciones experimentales, todos los participantes respondieron una prueba de comprensión. La capacidad de procesamiento de la forma se examinó a través una prueba de reconocimiento de las estructuras del pasado, una prueba escrita de producción, y una prueba de traducción. Los resultados de una prueba bifactorial de varianza con los resultados de la prueba de comprensión revelaron un efecto significativo para los ILTs. Los resultados de una prueba bifactorial para analizar los efectos de la condición - ILT en la capacidad de los participantes de procesar la forma en las tres pruebas de comprensión revelaron ciertos beneficios. Al comparar tal beneficio entre las tres pruebas, los resultados de los análisis de varianza no revelaron diferencia alguna. Estos resultados sugieren que el procesamiento del «input» en esta condición se vio beneficiado por el proceso de pensamiento en voz alta y no por la prueba de reconocimiento de la forma. Los resultados de los análisis de varianza no revelaron interacción alguna entre los tipos de textos y la condición de ILT. Sin embargo, el procesamiento del «input» sí se vio influenciando por tal interacción.

Palabras clave: Procesamiento del «input»; comprensión; indicadores léxico-temporales

\section{INTRODUCTION}

The truism that human communication takes place primarily for getting message across holds true about L2 as well. The «communicative intent» or message negotiated through an interaction is highlighted when the simple dichotomy is made between form and meaning as two components of any piece of language which is produced for communication. There is now a consensus among SLA researchers (e.g., Færch and Kasper, 1986; Krashen, 1982; VanPatten, 1996, 2004a) that learners primarily attend to the message during interaction in an L2. The very first principle of Input Processing (IP) acknowledges that «Learners process input for meaning before they process it for form» (VanPatten, 2004a: 7).

Learners at early stages of acquisition struggle up the hill of L2 acquisition which calls for processing input. Processing the input simultaneously for form and meaning can double the trouble for the learner. Another observation which might make the situation sound more complex is the intimate connection between form and meaning which has to be established for extracting the message.

The claim that learners tend to use a meaning-based approach as the default when processing input (VanPatten, 1996) is predicated upon information processing theory which considers that human beings have a limited and finite capacity for processing information (MacLaughlin, 1987). This restriction is likely to urge L2 learners to be selective.

According to Skehan (1996, 1998; Skehan and Foster, 2001), attention of learners is limited to a single-resource with limited capacity. Due to individuals' differences in attentional capacity (Schmidt, 1990; Skehan, 1998) which influence SLA in general (Robinson, 1995) and the on-line computations during comprehension in particular, and the «capacity robbing» nature of L2 comprehension (Just and Carpenter, 1992) as well as the taxing nature of comprehension for beginning and intermediate learners (VanPatten, 2004a), attending to form and meaning might prove to be beyond language learners' ken. 
Real time demand (Skehan, 1998) is hypothesized to push L2 learners to be selective in processing content word at the expense of morphosyntactic processing (Harrington, 2004). Selectivity is considered to be a corollary of limited capacity of attention that requires it to be strategically and economically allocated to identifiable referential meaning by using a costbenefit analysis (Schmidt, 2001). Therefore, limited attentional resources absorb and filter those elements that carry identifiable message/meaning rather than communicatively redundant, abstract formal features (Lee, Cadierno, Glass, and VanPatten, 1997; VanPatten, 1996, 2004a, 2004b).

The lexical preference principle (LPP), which is a subprinciple of IP, claims that learners might have a tendency to rely on lexical items rather than grammatical markers to get meaning when the same semantic information is encoded by both of them equally (VanPatten, 2004a). The primacy of meaning principle and the LPP confirm the claim that meaning is given priority when form and meaning compete for attention.

Employing the LPP the present study aims to see whether the presence of lexical temporal indicators (LTIs, i.e., lexical cues to the time frame of a given phrase, e.g. temporal adverbs, a form of a date) in a text contribute to the quality of comprehension and whether processing a morphosyntactic feature - apparently communicatively redundant and an abstract feature - which signal the same meaning encoded by these indicators is affected negatively. The performance of the participants is to be measured under online nonmetalinguistic thinkaloud protocol and silent-reading conditions.

\section{REVIEW OF LITERATURE}

Among the studies which have given support to the LPP and implicitly the primacy of meaning principle are those which have focused particularly on LTIs and its role in comprehension and input processing using different methodological options (Lee, 1999, 2002; Lee et al., 1997; Musumeci, 1989, cited in Rossomondo, 2007).

Musumeci (1989, cited in Rossomondo, 2007) investigated this phenomenon at sentence level. Each target sentence contained a temporal adverb in +LTIs condition. Since the mode of the input employed was aural and learners were required to listen to the sentences played. To determine the level of comprehension the learners were required to do just a multiplechoice test. The learners in the +LTI conditions were reported to comprehend significantly higher than the learners in the «LTI conditions.

Lee et al. (1997) studied the effect of LTIs on comprehension and input processing at discourse level; LTIs were included in every sentence that contained a target verb in one version of the passages, and in the second version all LTIs were deleted. The mode of the input was aural. A free written recall in the learners' native language was employed to measure comprehension and a multiple-choice tense identification test was used to measure input processing. In the written recall, the presence of adverbs improved comprehension significantly. In the tense-identification test, the presence of adverbs made the effect approach a level of statistical significance.

Lee (1999) conducted an exploratory study with a limited subject pool using passages adapted from Lee et al. (1997). One version of the passages contained a time adverb and a morphologically marked target verb in each sentence and no time adverb in the other version. 
The participants were asked to think aloud as they read the passage. Analyzing the concurrent think-aloud protocols of participants, Lee found that learners would often rely on lexical clues in order to establish temporality. In the absence of LTIs, their reliance was on background knowledge for making temporal framework.

Lee (2002) investigated the frequency of exposure to the target form in addition to the study of the role of LTIs in comprehension and input processing. He prepared three exposure conditions that contained 6, 10 or 16 target forms and LTIs in each reading passage. For each of these three texts, the other version was then prepared without LTIs. Participants read the passages silently. Lee made use of various means of measuring comprehension and input processing. To measure comprehension, he employed both a free written recall and a multiplechoice comprehension test in the learners' native language. To measure input processing, Lee utilized a form-production test in the form of cloze passage in Spanish (completed by one half of the participants) and a form-recognition test (completed by the other half). Lexical cues significantly enhanced the learners' comprehension measured by a free recall test, but not in multiple-choice comprehension questions. Neither of the tests measuring input processing showed any significant form-meaning connections.

Rossomondo (2007) investigated the effect of the presence or absence of LTIs on comprehension and input processing of an unfamiliar morphological form in two text interaction formats, i.e., silent reading and a think-aloud protocol. After reading the passage, all 4 participants completed the same multiple-choice comprehension test. To measure input processing, half of the participants in each condition completed a multiple-choice form-recognition test and the other half completed a cloze passage production test. LTIs enhanced comprehension. The presence or absence of lexical cues to meaning did not affect the learners' noticing of the novel forms in the input.

In sum, neither of these studies supports the inhibitory role attributed to LTIs regarding input processing. Lee (1999, 2002), Lee et al. (1997), Musumeci (1989, cited in Rossomondo, 2007), and Rossomondo (2007), however, provided some support for the positive effects of the presence of these lexical cues on comprehension or learners' ability to get meaning from the input.

\section{RESEARCH QUESTIONS}

The present study seeks to answer the following research questions:

- Would the presence or absence of LTIs as a cue to meaning affect comprehension of the propositional content of a passage during a silent reading or on-line nonmetalinguistic think-aloud protocol?

- Would the presence or absence of LTIs as a cue to meaning affect input processing of a new morphological form in a passage (in terms of form recognition and form production) during a silent reading or online nonmetalinguistic think-aloud protocol?

- What is the role of the text interaction format (online nonmetalinguistic think-aloud protocol or silent reading condition) in learner comprehension and input processing? 


\section{Method}

\subsection{Participants}

The participants of this study were 161 Azari learners of English at some Language Institutes and Shahid Khalaban Zaker junior high school in Ardabil who were unfamiliar with the target morphology (simple past tense with regular verbs) as it was shown by the pre-test. Their knowledge of the past tense was determined based on participants' scores on a screening test of verb form knowledge which was administered to 260 language learners who voluntarily took the test. The results of the ANOVA test run showed that there was no significant difference across the 8 groups of participants $\left(F_{(7,153)}=1.62, p=.187\right)$. Based on the results obtained, the 8 groups of the study were taken to be homogenous in terms of the form in focus.

The learners whose scores ranged between 9 and 14 were asked to participate in the study. The number of items was 28 in total. Fourteen out of these 28 items had been conjugated in simple present and present progressive. One point was assigned for each correct answer. The participants whose ages were about 14 were randomly assigned to four main groups: silent reading +LTI, silent reading «LTI, think-aloud +LTI, and think-aloud «LTI. Each main group, i.e., +LTI and «LTI (silent reading) and +LTI and «LTI (think-aloud) were further divided into two sub-groups to counterbalance them in terms of input processing measurements, i.e., on the basis of the order of form-recognition and cloze-passage production test which they received. This was done primarily for ruling out test-effect.

\subsection{Materials}

The materials used in this study included a packet that consisted of an informed consent statement, a language experience background questionnaire, a screening test of verb form knowledge, and a reading passage with or without LTIs. The passage prepared included 14 target forms -ed with approximately one target form per sentence. One version of the narrative began with a title that referred to the past (John's last year experience) and contained one LTI in each sentence in which a target form appeared. The LTIs included dates and temporal adverbs (such as, yesterday) as well as noun phrases (e.g., a few days ago or last year), but in the second version of the passage, no LTIs and title appeared.

To determine which structures to be included in the pre-test serving as choices, some further pilot studies were performed over simple present, simple past, present perfect, and simple future, and present progressive. Finally, simple present, present progressive, simple past, and simple future were selected and assigned in random order.

In order to measure comprehension, a 14-item multiple-choice comprehension test was developed. The purpose of the test was to determine whether participants could comprehend the past meaning of the sentence in the passage. It included one item for each target verb in the passage, in the order in which they originally appeared in the passage. The items were made up of sentences from the «LTI version of the passage translated into Persian. There was a blank for each target verb. All 14 items in the test included sentences that would make sense with any of the choices listed.

To determine which structures to be included in the multiple-choice comprehension test as choices, some pilot studies were implemented over simple present, simple past, simple 
future, past perfect, present progressive, present perfect. Four structures were selected; simple present, simple past, present perfect and future structure.

In order to measure input processing, a form-recognition test (multiple-choice test) and two form-production tests (a cloze-passage production test and a translation test) were included that required participants to demonstrate if they had detected and processed the novel forms in the input.

The purpose of the multiple-choice form-recognition test was to determine if learners could notice or detect (Tomlin and Villa, 1994) the novel forms in the input as they read the text. In other words, the multiple-choice form-recognition test might reflect whether the participants had at least begun processing the new forms to which they had been exposed in the passage. The test included 14 items in English without LTIs. It corresponded with the target sentences in the passage and in the order in which they had originally appeared. There was a blank in the place of the verb in each sentence, and below each item there were three choices in random order: the target verb conjugated in simple present, simple past and infinitive form of the verb. The reason for choosing simple present and simple past was that the test needed inflectional morphology and simple present was the only structure which takes the inflectional morphology -s when it is conjugated in third person singular, and it is a structure which does not take any morphology when it is conjugated in plural forms. The only morphology for simple past was -ed in all of its conjugated forms. Totally, three choices for multiple-choice form-recognition test (simple present with third person singular -s, the infinitive form of verb, and simple past) were selected and randomly assigned in the test. The participants were to select the form of the word that appeared in the passage.

In order to make sure that participants were able to process the new forms to the extent that they would be able to produce the form, a cloze passage production test was administered. It consisted of the same passage without LTIs. In each sentence, the conjugated target verb was replaced by a blank space followed by the infinitive form of the target verb in parentheses. The participants were instructed to conjugate the verb in parentheses in the same form as it appeared in the passage.

According to Rossomondo (2007), the form recognition and cloze-passage tests do not demonstrate whether forms have been connected to their meaning or not. Therefore, it seemed imperative to develop tests which could vividly mirror the end point of input processing. Translation test is argued to be the most demanding production test which requires learners to activate their previous knowledge to connect form to meaning. In the present study, in order to produce the correct form, the learner must have processed the new form. Therefore, it was judged to be an appropriate test to get assurance that the form had been processed.

The test included 14 items in Persian with the infinitive form of the target verbs in parentheses. Eight sentences were written in simple past and six of them were written in simple present. The purpose of including simple present sentences was to make it challenging enough for learners and not to direct them to the structure intended. The simple present sentences were ignored after administering the test and just simple past sentences were scored.

\subsection{Procedure}

In order to identify those participants who already possessed some knowledge of the simple past tense, and exclude their data from analysis, a test of verb form knowledge serving 
as the pre-test was administered. But before giving any pre-test a language experience background questionnaire was administered asking participants to disclose the number of years of learning English as well as any other languages they had studied.

To demonstrate what the participants were expected to do clearly, the materials in the think-aloud condition included an example of an online, nonmetalinguistic think-aloud protocol. A warm-up passage was included in the study packet in order to provide the participants with an opportunity to familiarize themselves with performing a think-aloud protocol. However, the participants were not informed that this think-aloud protocol was being conducted as a warmup and would not be included as part of the data for the present study.

The +LTI groups read a version of the passage that included lexical clues to meaning in addition to the verb morphology and the title, whereas the «LTI groups read a version of the passage with the verb morphology only without the title and lexical clues, and their silentreading and think-aloud data were collected. The think-aloud data were collected by the researchers with audio-recording equipment.

All participants of the study in the \pm LTIs groups during think-aloud protocol and silent reading condition completed a comprehension test. Then participants were counterbalanced on the form-recognition and the cloze-passage tests and next were required to complete the translation test.

\section{RESULts}

As it was mentioned earlier, in this study the concern has been with exploring the effects of the presence and absence of LTIs on L2 learner comprehension and input processing of an unfamiliar target morphology during text interaction formats, i.e., silent reading and thinkaloud protocol condition.

Since there were eight \pm LTIs groups during silent reading and think-aloud protocol based on the order of form-recognition and cloze-passage tests which these groups received, eight $t$-tests were conducted which showed no statistically significant differences among the counterbalanced groups based on which we became confident that test-effect did not influence the performance on the second test significantly.

The first research question addressed the effects of two independent variables, namely the \pm LTIs and text interaction format (silent reading vs. think-aloud protocol) on the comprehension of the propositional content of the text. Table 1 shows the descriptive statistics for comprehension. 
Table 1. Descriptive statistics for comprehension test.

\begin{tabular}{|c|c|c|c|c|}
\hline Condition & LTI & N & Mean & SD \\
\hline Silent & + & 46 & 8.35 & 3.36 \\
& - & 51 & 6.00 & 3.39 \\
Total & & 97 & 7.11 & 3.56 \\
\hline Aloud & + & 34 & 7.71 & 3.40 \\
& - & 30 & 6.00 & 3.30 \\
Total & & 64 & 6.91 & 3.43 \\
\hline Total & + & 80 & 8.08 & 3.37 \\
& - & 81 & 6.00 & 3.33 \\
Total & & 161 & 7.03 & 3.50 \\
\hline
\end{tabular}

A two-way ANOVA was conducted to examine the effects of LTIs and text interaction format on comprehension. The results of the test run are presented in Table 2. The main effect of the text interaction format was not statistically significant $\left(F_{(3,157)}=0.35, p=.555\right)$. Looking at the \pm LTIs effect, it becomes clear that the main effect of \pm LTIs was statistically significant $\left(F_{(3,157)}=13.94, p<.0001\right)$, though a small effect size appeared to exist for the +LTIs $(d=$ $.015)$. As it is clear in Table 2, the result obtained for the interaction of the text interaction format and LTIs did not turn out to be statistically significant $\left(F_{(3,157)}=0.35, p=.555\right)$. As it seems to be the case, comprehension benefited from the presence of LTIs, while no significant effect was observed to be exercised on the dependent variable of the study as a result of text interaction format alone and the interaction of the text interaction format and LTIs condition.

Table 2. Two-way ANOVA results for comprehension test.

\begin{tabular}{|c|r|r|r|r|r|r|}
\hline Source & \multicolumn{1}{c|}{ SS } & \multicolumn{1}{c|}{$\mathrm{df}$} & \multicolumn{1}{c|}{ MS } & $F$-Value & \multicolumn{1}{l|}{ Sig. } & \multicolumn{1}{c|}{$d$} \\
\hline TIF & 3.96 & 1 & 3.96 & .35 & .555 & .000 \\
\hline LTI & 157.87 & 1 & 157.87 & 13.94 & $.000^{* * *}$ & .015 \\
\hline TIF*LTI & 3.96 & 1 & 3.96 & .35 & .555 & .000 \\
\hline Error & 1777.49 & 157 & 11.32 & & & \\
\hline Total & 9918.00 & 161 & & & & \\
\hline
\end{tabular}

The post-hoc LSD tests run for the effect of \pm LTIs and text interaction format on comprehending the propositional content of the text showed that the difference between the $+\mathrm{S}$ and $« \mathrm{~S}$ and $+\mathrm{A}$ and $« \mathrm{~A}$ were statistically significant $(p=.001, p=.045$, respectively). The difference between $+\mathrm{S}$ and $+\mathrm{A}$ and also $« \mathrm{~S}$ and $« \mathrm{~A}$ did not reach statistical significance $(p=$ $.400, p=1.00$, respectively). Comprehension did not benefit from text interaction format in the absence of LTIs (Table 3 ). 
Table 3. Differences in comprehension according to \pm LTIS and text interaction forma.

\begin{tabular}{|c|c|c|c|c|}
\hline Source & $\mathrm{N}$ & Mean & SD & Sig. \\
\hline $\begin{array}{l}+\mathrm{S} \\
-\mathrm{S}\end{array}$ & $\begin{array}{l}46 \\
51\end{array}$ & $\begin{array}{l}8.35 \\
6.00\end{array}$ & $\begin{array}{l}3.36 \\
3.39\end{array}$ & $.001^{* *}$ \\
\hline $\begin{array}{l}+\mathrm{S} \\
+\mathrm{A}\end{array}$ & $\begin{array}{l}46 \\
34\end{array}$ & $\begin{array}{l}8.35 \\
7.71\end{array}$ & $\begin{array}{l}3.36 \\
3.40\end{array}$ & .400 \\
\hline $\begin{array}{l}-\mathrm{S} \\
-\mathrm{A}\end{array}$ & $\begin{array}{l}51 \\
30\end{array}$ & $\begin{array}{l}6.00 \\
6.00\end{array}$ & $\begin{array}{l}3.39 \\
3.29\end{array}$ & 1.00 \\
\hline $\begin{array}{l}+\mathrm{A} \\
-\mathrm{A}\end{array}$ & $\begin{array}{l}34 \\
30\end{array}$ & $\begin{array}{l}7.71 \\
6.00\end{array}$ & $\begin{array}{l}3.40 \\
3.29\end{array}$ & $.045^{*}$ \\
\hline
\end{tabular}

The main effects of text interaction format, \pm LTIs, and the interaction effect of the two independent variables on the input processing of the unfamiliar target morphology -ed were at the core of research question 2. It has to be pointed out in passing that input processing was measured through three different tests: a multiple-choice form-recognition test, a cloze passage production test, and a translation test. Three two-way ANOVAs were run on the data obtained from silent reading and think-aloud protocol groups receiving \pm LTIs.

Tables 4 through 6 show the descriptive statistics for the effects of \pm LTIs and text interaction format on input processing measured by the multiple-choice form-recognition test, the cloze-passage production test, and the translation test.

Table 4. Descriptive statistics for input processing (Form-recognition test).

\begin{tabular}{|c|c|c|c|c|}
\hline ondition & LTI & $\mathrm{N}$ & Mean & $\mathrm{SD}$ \\
\hline Silent & \multirow{3}{*}{$\begin{array}{l}+ \\
-\end{array}$} & 46 & 5.93 & 3.74 \\
\hline & & 51 & 6.73 & 3.29 \\
\hline Total & & 97 & 6.35 & 3.52 \\
\hline Aloud & \multirow{3}{*}{$\begin{array}{l}+ \\
-\end{array}$} & 34 & 6.85 & 4.94 \\
\hline & & 30 & 7.33 & 4.61 \\
\hline Total & & 80 & 6.33 & 4.28 \\
\hline Total & \multirow{3}{*}{$\begin{array}{l}+ \\
-\end{array}$} & 80 & 6.33 & 4.28 \\
\hline & & 81 & 7.95 & 3.82 \\
\hline Total & & 161 & 6.64 & 4.06 \\
\hline
\end{tabular}


Table 5. Descriptive statistics for input processing (Cloze-passage test).

\begin{tabular}{|c|c|c|c|c|}
\hline ondition & LTI & N & Mean & SD \\
\hline Silent & + & 46 & 3.26 & 4.23 \\
& - & 51 & 5.98 & 4.25 \\
Total & & 97 & 4.69 & 4.43 \\
\hline Aloud & + & 34 & 6.82 & 5.01 \\
& - & 30 & 6.37 & 4.78 \\
Total & & 64 & 6.61 & 4.87 \\
\hline Total & + & 80 & 4.78 & 4.88 \\
& - & 81 & 6.12 & 4.49 \\
Total & & 161 & 6.45 & 4.69 \\
\hline
\end{tabular}

Table 6. Descriptive statistics for input processing (translation test).

\begin{tabular}{|c|c|c|c|c|}
\hline Condition & LTI & N & Mean & SD \\
\hline Silent & + & 46 & 1.59 & 2.44 \\
& - & 51 & 2.49 & 2.55 \\
Total & & 97 & 2.06 & 2.52 \\
\hline Aloud & + & 34 & 3.62 & 2.09 \\
& - & 30 & 3.00 & 2.91 \\
Total & & 64 & 3.39 & 3.00 \\
\hline Total & + & 80 & 4.45 & 2.90 \\
& - & 81 & 2.68 & 2.68 \\
Total & & 161 & 2.57 & 2.79 \\
\hline
\end{tabular}

The results obtained from the two-way ANOVA run on the data and presented in Table 7 show that the main effect of the text interaction format for the form-recognition test was not statistically significant $\left(F_{(3,157)}=1.36, p=.246\right)$. The story appeared to be the same for the main effect of \pm LTIs treatment. The difference between the +LTIs and «LTIs, as the two-way ANOVA results showed, was not statistically significant $\left(F_{(3,157)}=.94, p=.334\right)$. Nor was there any statistically significant difference when the interaction effect of the two independent variables was considered $\left(F_{(3,157)}=.056, p=.813\right)$, suggesting that there were no significant effects flowing from text interaction format, LTIs, and the interaction of these two independent factors on L2 learners' input processing examined through a form-recognition test. 
Table 7. Two-way ANOVA results for input processing (form-recognition test).

\begin{tabular}{|c|c|c|c|c|c|c|}
\hline Source & SS & $\mathrm{df}$ & MS & $F$-Value & Sig. & $d$ \\
\hline TIF & 22.37 & 1 & 13.07 & 1.36 & .246 & .002 \\
\hline LTI & 15.52 & 1 & 15.52 & .94 & .334 & .001 \\
\hline TIF*LTI & .925 & 1 & .925 & .056 & .813 & .000 \\
\hline Error & 2591.89 & 157 & 16.51 & & & \\
\hline Total & 9729.00 & 161 & & & & \\
\hline
\end{tabular}

The post-hoc analyses conducted (Table 8) reported that the difference between $+\mathrm{S}$ and $\ll \mathrm{S},+\mathrm{S}$ and $+\mathrm{A}$, $« \mathrm{~S}$ and $« \mathrm{~A}$, and $+\mathrm{A}$ and $-\mathrm{A}$, did not reach the point to be statistically significant $(p=.340, p=.319, p=.517$, and $p=.638$, respectively).

Table 8. Differences in input processing (form-recognition test).

\begin{tabular}{|c|c|c|c|c|}
\hline Source & $\mathrm{N}$ & Mean & SD & Sig. \\
\hline$+\mathrm{S}$ & 46 & 5.93 & 3.74 & .340 \\
$-\mathrm{S}$ & 51 & 6.73 & 3.29 & .340 \\
\hline$+\mathrm{S}$ & 46 & 5.93 & 3.74 & .319 \\
$+\mathrm{A}$ & 34 & 6.35 & 4.93 & .517 \\
\hline$-\mathrm{S}$ & 51 & 6.73 & 3.29 & \multirow{2}{*}{.617} \\
\hline $\mathrm{A}$ & 30 & 7.33 & 4.61 & .638 \\
\hline $\mathrm{A}$ & 34 & 6.35 & 4.93 & \multirow{2}{*}{$\mathrm{A}$} \\
\hline
\end{tabular}

The results of the two-way ANOVA (Table 9) on cloze-passage production test reflected that think-aloud protocol outperformed silent-reading condition $\left(F_{(3,157)}=5.31, p=.007\right)$ with a small effect size $(d=.018)$. Accordingly, the target morphology -ed seems to be processed in think-aloud protocol and not in silent reading. No significant difference was found between the + LTIs group and the «LTIs group $\left(F_{(3,157)}=237.33, p=.122\right)$, that is, the presence or absence of LTIs did not seem to play any significant role in input processing of -ed form in cloze-passage production test as the results of the ANOVA test conducted on the data indicated. When the interaction effect of the two independent variables was considered, the difference between them reached statistical significance $\left(F_{(3,157)}=2.42, p=.031\right)$, which reflected the fact that text interaction format plays an activating role for \pm LTI in cloze-passage production test, although the effect size appeared to be small $(d=.011)$. 
Table 9. Two-way ANOVA results for input processing (cloze-passage test)

\begin{tabular}{|c|c|c|c|c|c|c|}
\hline Source & SS & df & MS & $F$-Value & Sig. & $d$ \\
\hline TIF & 149.81 & 1 & 149.81 & 5.31 & $.007^{* *}$ & .018 \\
\hline LTI & 49.18 & 1 & 49.18 & 237.33 & .122 & .005 \\
\hline TIF*LTI & 49.18 & 1 & 96.93 & 2.42 & $.031^{*}$ & .011 \\
\hline Error & 3197.76 & 157 & 20.39 & 4.76 & & \\
\hline Total & 8310.00 & 161 & & & & \\
\hline
\end{tabular}

The post-hoc analyses run (Table 10) showed that the difference between $+\mathrm{S}$ and «S, on the one hand, and the one between $+\mathrm{S}$ and $+\mathrm{A}$, on the other, were large enough (significant at $p=.004$, and $p=.001$, respectively). The difference between the «S and «A $(p=.710)$ and the $+\mathrm{A}$ and $« \mathrm{~A}(p=.687)$, however, did not reach statistical significance in cloze-passage production test. Overall, the $+\mathrm{S}$ outperformed $« \mathrm{~S}$ and $+\mathrm{A}$. This means that + LTIs during silent reading were more effective than +LTIs during think-aloud protocol. Even +LTIs during silent reading performed better than «LTIs during silent reading.

Table 10. Differences in input processing (cloze-passage test).

\begin{tabular}{|c|c|c|c|c|}
\hline Source & $\mathrm{N}$ & Mean & $\mathrm{SD}$ & Sig. \\
\hline$+\mathrm{S}$ & 46 & 3.26 & 4.22 & \multirow{2}{*}{$.004 * *$} \\
\hline$-\mathrm{S}$ & 51 & 5.98 & 4.24 & \\
\hline$+\mathrm{S}$ & 46 & 3.26 & 4.22 & \multirow{2}{*}{$.001 * *$} \\
\hline$+\mathrm{A}$ & 34 & 6.82 & 5.00 & \\
\hline$-\mathrm{S}$ & 51 & 5.98 & 4.24 & \multirow{2}{*}{.710} \\
\hline$-\mathrm{A}$ & 30 & 6.37 & 4.24 & \\
\hline$+\mathrm{A}$ & 34 & 6.82 & 5.00 & \multirow{2}{*}{.687} \\
\hline$-A$ & 30 & 6.37 & 4.75 & \\
\hline
\end{tabular}

As it has been presented in Table 11, for the translation test, participants under thinkaloud protocol outperformed those under silent reading condition $\left(F_{(3,157)}=3.98, p=.004\right)$. The effect size was small $(d=.026)$. The main effect of the +LTIs group and «LTI group was not statistically significant $\left(F_{(3,157)}=149.59, p=.744\right)$ indicating that there was no difference in terms of including LTIs or excluding them. As it can be observed, the interaction effect of text interaction format and LTIs treatment was not significant $\left(F_{(3,157)}=8.44, p=.084\right)$, though a trend for the interaction of text interaction format and LTIs groups was observed $(p=.084)$. Generally viewed, the ANOVA results reflected significant effects flowing from text interaction format, and the interaction effect of \pm LTIs and text interaction format on L2 learners' input processing examined through a translation test. 
Table 11. Two-way ANOVA results for input processing (translation test).

\begin{tabular}{|c|c|c|c|c|c|c|}
\hline Source & SS & df & MS & $F$-Value & Sig. & $d$ \\
\hline TIF & 62.00 & 1 & 62.00 & 3.98 & $.004^{* *}$ & .026 \\
\hline LTI & .784 & 1 & .784 & 149.50 & .744 & .000 \\
\hline TIF * LTI & 22.22 & 1 & 22.22 & 8.44 & .084 & .009 \\
\hline Error & 1153.93 & 157 & 7.35 & .107 & & \\
\hline Total & 2301.00 & 161 & & 3.02 & & \\
\hline
\end{tabular}

The post-hoc analyses conducted (Table 12) revealed that the main effect of $+\mathrm{A}$ was greater than that of $+\mathrm{S}(p=.001)$. However, the analyses did not reveal statistically significant difference for $+\mathrm{S}$ vs. $« \mathrm{~S}(p=.103),+\mathrm{A}$ vs. $« \mathrm{~A}(p=.364)$, and $« \mathrm{~S}$ vs. «A $(p=.415)$. It can be concluded that think-aloud in the presence of LTIs was of considerable effect on the input processing of -ed through translation test.

Table 12. Differences in input processing (translation test).

\begin{tabular}{|c|c|c|c|c|}
\hline Source & $\mathrm{N}$ & Mean & SD & Sig. \\
\hline$+\mathrm{S}$ & 46 & 1.59 & 2.47 & .103 \\
\hline$-\mathrm{S}$ & 51 & 2.49 & 2.54 & \\
\hline$+\mathrm{S}$ & 46 & 1.59 & 2.47 & $.001^{* *}$ \\
$+\mathrm{A}$ & 34 & 3.62 & 3.09 & \\
\hline$-\mathrm{S}$ & 51 & 2.49 & 2.54 & .415 \\
$-\mathrm{A}$ & 30 & 3.00 & 2.91 & \\
\hline$+\mathrm{A}$ & 34 & 3.62 & 3.09 & .364 \\
$-\mathrm{A}$ & 30 & 3.00 & 2.91 & \\
\hline
\end{tabular}

\section{Discussion}

Central to the present study was to determine the effects of LTIs on creating meaning from a simple text and processing a morphosyntactic feature by beginning learners when they confronted with some new forms in the input. In light of the results obtained it can be argued that providing LTIs along with some new forms which refer to the same meaning (time of an action in this specific case) give L2 learners a better chance of understanding the content of a text. Depriving beginning learners of these indicators might render the text fairly difficult for such learners while providing them with these indicators are likely to facilitate getting meaning from these lexical items. Viewed in the context of IP and the LPP framework, the findings can be clearly interpreted as follows: since the participants in the present study were beginners and the demands placed upon them were meaning-oriented in nature, they had to attend to meaning or understanding the text and had little or no processing capacity to allocate to the unfamiliar verb tense embedded in the text. Differently stated, the participating learners made an attempt 
to process the text for meaning before sparing any time to process it for form. On the other hand, since the time of action could be signaled by some lexical cues including temporal adverbs, dates, nouns and adjectives, they could take advantage of these lexical cues for comprehending the text without experiencing any difficulty. As a result, this group of participants turned out to outperform the participants in the group which was not provided with LTIs and were left to induce the past tense from the morpheme -ed attached to verbs.

This study complements positive findings in Lee's (1999, 2002), Lee et al.'s (1997), Musumeci (1989, cited in Rossomondo, 2007) and Rossomondo's (2007) studies which employed VanPatten's (2004a) LPP and found benefits for +LTIs. While the positive effects of LTIs on creating meaning from the text appeared to be limited to the silent reading format in the studies just mentioned, in this study the effects turned out to be significant in the think aloud format as well.

The results also lend support to Rossomondo's (2007) argumentation that whenever LTIs appear to be present in the input, beginning learners of language might use verb-specific time frame rather than general time frame. A verb-specific time frame implies those LTIs that cooccur with each target verb while general time frame includes those LTIs whose occurrence is occasional.

The positive effects found for +LTIs upon reading comprehension can also be justified according to VanPatten's (2004a) LPP subprinciple which claims that morphological form of the verb does not attract learners' attention if there are additional cues (e.g., lexical cues) to extract the same semantic information; therefore, forms are not attended to by the learner due to the presence of LTIs. Put differently, according to the LPP, learners prefer lexical cues present in the input over grammatical form if they happen to encode the same semantic information. This finding, in conjunction with those of Lee (2002) and Rossomondo (2007), gives empirical evidence to argue for the LPP regarding L2 reading comprehension.

While a clear pattern was found for the positive effects exercised by the presence of LTIs upon L2 reading comprehension regarding beginning learners of English in the context this study was conducted, no such pattern could be traced regarding the positive effects of the absence of LTIs upon input processing. The findings went against the hypothesis made. Employing VanPatten's LPP we expected L2 learners to be urged to attend to the morphosyntactic form in the absence of LTIs. Put differently, when there is no lexical cue present in a text it stands to reason to expect L2 readers to search for some other language elements to aid them to understand the text.

This struggle in pursuit of extracting the propositional content of a text in the absence of lexical cues is hypothesized to lead to intimate engagement of L2 learners with morphosyntactic structure signaling the meaning shared by the lexical cue/s and the morphosyntactic element. Viewed from theoretical angle, the learner might have a better chance of noticing the form under such an input condition. But this study, in conjunction with Lee (2002) and Rossomondo (2007), provides no empirical evidence to support this claim partially due to the simple fact that the study was conducted one-shot leaving no time for the structure to be deeply processed by the participants. More importantly, there was no external triggering force to make the participating learners to understand the text provided. Then they possibly didn't make any attempt to get cognitively involved in processing the text for extracting the meaning out of it.

Such a claim can be easily verified through taking a second look at the results presented. In the results section we delineated that the +LTIs group outperformed the -LTIs group. We 
can logically conclude that there have not been equal degrees of understanding in +LTIs and -LTIs to claim that the absence of LTI did not contribute to L2 processing as it is argued to be the case theoretically. Simply stated, if we intend to observe the effects of LTIs in processing L2 form signaling the time frame, some certain degrees of reading comprehension should be established.

In sum, the presence of LTIs in a simple text developed for beginning L2 learners can mitigate the difficulty of making sense of the text even if they happen to attend to some new morphosyntactic structure. The facilitative role of these indicators has to do with their lexical nature which does not call for deeper processing as morphosyntactic structures do. Such a facilitative role, however, is argued to be detrimental to learning process because L2 learners do not see any need for processing the new form and chances for noticing such a form might slim down.

\section{Conclusion}

The findings of this study suggest that +LTIs enhance learners' comprehension as claimed by VanPatten's (2004a) LPP subprinciple. With respect to form processing and VanPatten's LPP, the results of the present study did not indicate that the presence of + LTIs serves to distract learners from noticing new forms.

Regarding the role of text interaction format, it exercises no main effect on learners' ability to comprehend the propositional content of the text. The think-aloud protocol format had an impact on processing -ed morphology as measured by the cloze-passage production test and the translation test. However, it had no effect on processing the intended form in the formrecognition test.

The interaction of \pm LTIs and text interaction format did not affect comprehension and input processing measured by the form-recognition test. However, it influenced processing ed measured by the cloze-passage test and reflected a trend for the translation test. Generally viewed, input processing was influenced by the text interaction format alone and the interaction of \pm LTIs and text interaction format.

\section{REFERENCES}

Færch, C. and Kasper, G. (1986). «Cognitive dimensions of language transfer», in E. Kellerman and M. Sharwood Smith (eds.), Cross-linguistic Influence in Second Language Acquisition, Oxford: Pergamon Press, 49-65.

Harrington, M. (2004). "Commentary: Input processing as a theory of processing input», in B. VanPatten (ed.), Processing: Theory, Research, and Commentary, Mahwah, NJ: Lawrence Erlbaum, 79-96.

Just, M. A. and Carpenter, P. A. (1992). «A capacity theory of comprehension: Individual differences in working memory», in Psychological Review, 99, 1: 122-149.

Krashen, S. (1982). Principles and Practice in Second Language Acquisition. Oxford: Pergamon.

Lee, J. F. (1998). «The Relationship of verb morphology to second language reading comprehension and input processing», in Modern Language Journal, 82, 1: 33-48. 
Lee, J. F. (1999). «On levels of processing and levels of comprehension», in J. Gutiérrez-Rexach and F. Martínez-Gil (eds.), Advances in Hispanic Linguistics, Somerville, MA: Cascadilla Press, 42-59.

Lee, J. F. (2002). «The incidental acquisition of Spanish future tense morphology through reading in a second language», in Studies in Second Language Acquisition, 24, 1: 55-80.

Lee, J. F., Cadierno, T., Glass, W. and VanPatten, B. (1997). «The effects of lexical and grammatical cues on processing past temporal reference in second language input», in Applied Language Learning, 8, 1: 1-23.

McLaughlin, B. (1987). Theories of Second Language Acquisition. London: Edward Arnold.

Robinson, P. (1995). "Attention, memory and the «noticing» hypothesis», in Language Learning, 45, 2: 283-331.

Rossomondo, A. (2007). «The role of lexical temporal indicators and text interaction format in the incidental acquisition of the Spanish future tense», in Studies in Second Language Acquisition, 29, 1: 39-66.

Schmidt, R. (1990). «The role of consciousness in second language learning», in Applied Linguistics, 11, 2: 129-158.

Schmidt, R. (2001). «Attention», in P. Robinson (ed.), Cognition and Second Language Instruction. Cambridge: Cambridge University Press, 3-32.

Skehan, P. (1996). «A framework for the implementation of task-based instruction», in Applied Linguistics, 17, 1: 38-62.

Skehan, P. (1998). A Cognitive Approach to Language Learning. Oxford: Oxford University Press.

Skehan, P. and Foster, P. (2001). "Cognition and tasks», in P. Robinson (ed.), Cognition and Second Language Instruction. New York: Cambridge University Press, 183-205.

Tomlin, R. S. and Villa, V. (1994). «Attention in cognitive science and second language acquisition studies», in Studies in Second Language Acquisition, 16, 2: 183-202.

VanPatten, B. (1996). Input Processing and Grammar Instruction: Theory and Research. Norwood, NJ: Ablex.

VanPatten, B. (2004a). «Input processing in SLA», in B. VanPatten (ed.), Processing Instruction: Theory, Research, and Commentary. Mahwah, NJ: Lawrence Erlbaum, 5-32.

VanPatten, B. (2004b). «Input and output in establishing form-meaning connections», in B. VanPatten, J. Williams, S. Rott, and M. Overstreet (eds.), Form-meaning Connections in Second Language Acquisition. Mahwah, NJ: Lawrence Erlbaum, 1-26. 